\title{
Classification System for the Interpretation of the Braille Alphabet through Image Processing
}

\author{
Brian Meneses-Claudio*, Witman Alvarado-Diaz, Avid Roman-Gonzalez \\ Universidad de Ciencias y Humanidades, Image Processing Research Laboratory (INTI-Lab), Perú
}

\begin{tabular}{l} 
A R T I C L E I N F O \\
\hline Article history: \\
Received: 15 October, 2019 \\
Accepted: 28 January, 2020 \\
Online: 20 February, 2020 \\
\hline
\end{tabular}

Keywords:

Braille Language

Image Processing

Point Detection

Visual Disability

Braille Language Translation

Peruvian Vocabulary

Braille Language Specialists

\begin{abstract}
A B S T R A C T
The Braille language system or also known as the language for the blind people was created so that these people can understand the vocabulary words depending on the country in which they are located, this system is based on points in which the points raised or also known as the largest points depending on their location will have a meaning of a letter. At present, very few educational centers have Braille translation systems or Braille language specialists for the understanding and teaching of people with visual disabilities. According to INEI, $1.9 \%$ of the Peruvian population has visual impairment and only $20 \%$ of that population manages to finish their studies thus having a great deficit in cognitive preparation. That is why a Braille translation system was proposed, capable of capturing images in Braille language and translating them through image processing into Peruvian vocabulary, giving as a result, the understanding of the person or specialist who is teaching or training in that moment. The Braille language image has to go through different filters of which are intended to obtain the areas of the circles that compose it in order to obtain a binary matrix of it and convert it to a number that will represent the letter. The result was the translation of the Braille language into Peruvian vocabulary and also the identification of the points that have each letter.
\end{abstract}

\section{Introduction}

The Braille system or also known as language for the blind is used by people who suffer or have some visual impairment or blindness, they require learning the Braille system to write and read texts, books and documents, this reading and writing system is tactile. These people tend to learn through audio but not by practicing motor hand movements, therefore, they will not be able to write or read texts in Braille [1].

According to the INEI (Instituto Nacional de Estadísticas e Informática), there are 600,000 people with visual disabilities in Peru, of which 160,000 suffer from general blindness and the other 440,000 have a disease related to blindness or loss of the vision [2]. However, being a large population, many public entities still do not integrate technology, training and rehabilitation systems so that young people with these ills can integrate and access primary, secondary or higher education.

The importance of the knowledge of the Braille system will allow the integration of these systems in the curricula for young people because it is estimated according to the INEI that $23.9 \%$ of the total population of people with visual disabilities manage to

${ }^{*}$ Corresponding Author: Brian Meneses-Claudio, bmeneses@uch.edu.pe

www.astesj.com

https://dx.doi.org/10.25046/aj050151 complete their studies, this problem implies that many blind people cannot work despite the fact that there is currently a general law 29973, which stipulates the integration of people with disabilities in the workplace, sectoring $5 \%$ in state entities and $3 \%$ in private companies [3].

The implementation of Braille Language Translation systems can help to reduce the gap that exists in the lack of knowledge of the same language and the knowledge of the importance of this language for people with visual disabilities [4]. According to the newspaper El Correo, it indicates that, among the most recurrent needs among blind children and young people, books adapted in braille and computers with the necessary technology are required to allow the student to access the information, being the most required audiobooks.

In [5], using image processing for the translation of the Braille language into the Spanish language, they have a preprocessing stage where they recognize the characters and then separate the information from each cell in order to obtain the 27 letters of the panish alphabet, this research work makes a comparison process with a database where they get the translation of the letters, also saves them in .txt format indicating the saving of the translated data. 
In [6], the research paper presents the design of a prototype of Braille language conversion to English vocabulary and vice versa, being easy to use for the person with visual impairment or blindness, at the moment the device is in the experimental phase, obtaining Good results, but the only drawback is that prior to the use of the electronic device, the person with visual impairment or blindness and the person without it, must be trained to use the equipment.

In [7], the research paper presents an electronic circuit with 6 buttons, this circuit will be able to obtain the Bangla language in text format and then convert it into a Braille code to finally be represented in binary code and thus through the Push buttons provide tactile understanding to people with visual impairment or blindness. In addition to the electronic circuit, it also has a buzzer that will emit sounds for periods of time depending on the radius of the points.

The main objective of the research work is to show the possibility of the implementation of image processing technologies for the translation of the Braille language into the Peruvian alphabet and the possibility of improving the social inclusion of people who have blindness or a disease related to blindness or loss of vision and also the implementation of these systems in educational centers so that these people can adapt to the education system.

Image processing is a set of techniques that are applied to digital images in order to improve or search for relevant information for a particular use. It is currently used for different lines of research such as satellite images in the detection of areas or biomedical for the detection of ills, as well as in this case of the research work in the area of processing and searching for information in an image to be extracted and then interpreted.

The following research work is structured as follows: In section II, the methodology of image processing of the text in Braille will be presented, in addition to presenting the flowcharts of the processes that were carried out to obtain the meaning of each image. In section III, the results of the research work will be shown through a table of accuracy about the tests performed and the percentage of acceptance in each of them. Finally, in section IV, the research work discussions will be presented and the conclusions on the research work will be presented as well as some recommendations for image processing.

\section{Methodology}

In this part, the steps for the processing of images for the translation of the Braille language into Spanish vocabulary are developed, which consist of the acquisition of the image, then find the centers of each of the characters and then separate them and find the centers and radii of the circles that make up each of the letters in Braille language, these steps are shown in Figure 1 in which at the end you get the letter in Braille format with the identification of the objects that make up the letter in Braille.

\subsection{Image Acquisition}

For the acquisition of an image, fragments of books were photographed and data on texts in Braille were downloaded from the Internet, then processed. This image must contain the visible points as shown in Figure 2, because it was noted that in many texts only large points are presented and for image processing it is preferable that the format which has all the points.

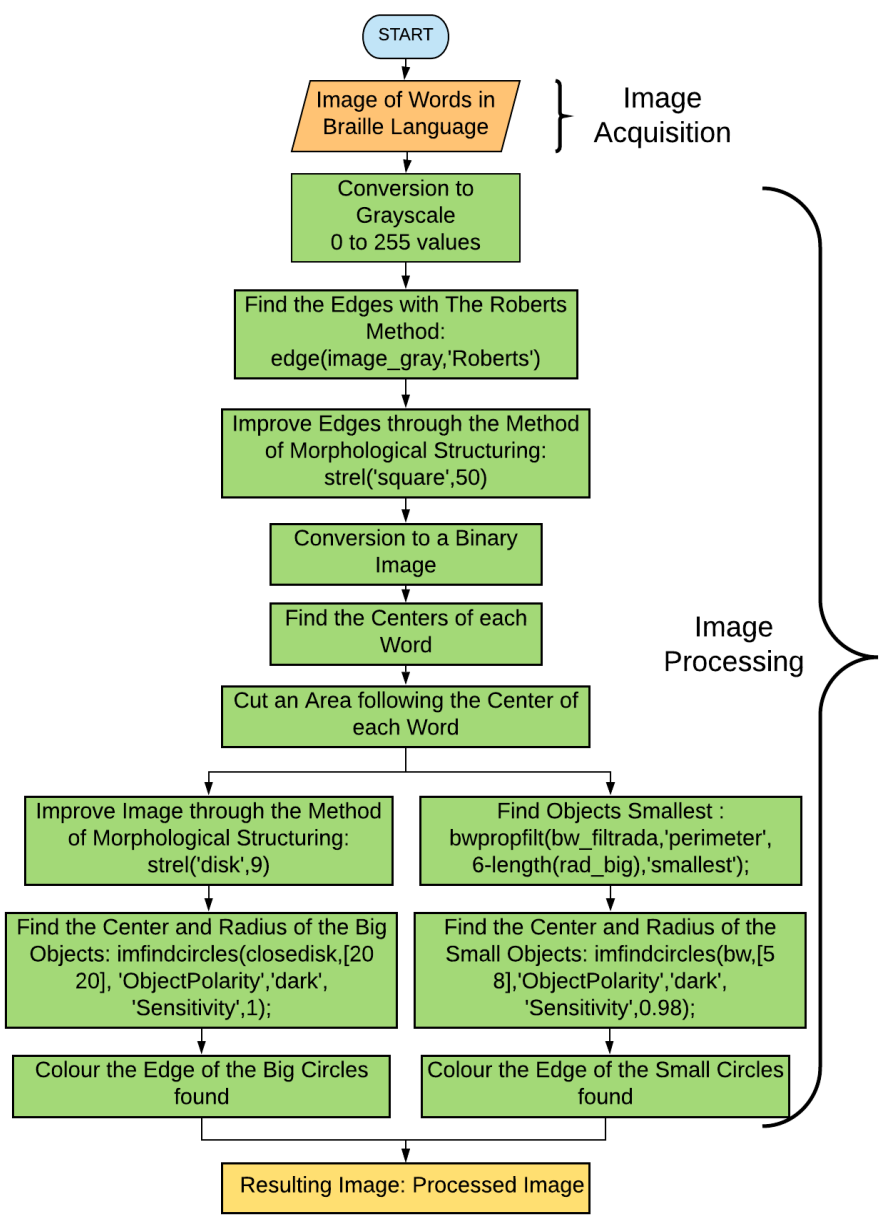

Figure 1: Process Flow Diagram for obtaining the Letter in Braille format and identifying its points.

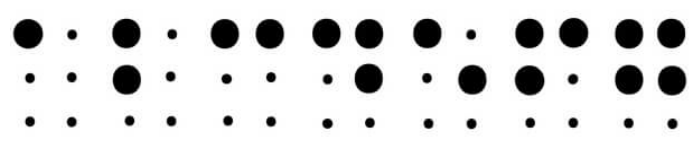

Figure 2: Letters in Braille Format showing large and small points.

In addition, it has to take into account the dimensions of each points because the diameter of the large points must be $1.2 \mathrm{~mm}$ and the separation of them between each point must be $2.5 \mathrm{~mm}$. Each of the letters in Braille must have a separation of approximately $2.3 \mathrm{~mm}$.

The scale of the dots in both cases (fragments of books and texts from Internet) are similar because they have the same dimension mention before. Also, these dimensions are international so there is no problem to analyze from different sources.

\subsection{Image Processing}

At this stage, the image that is entered is in 3 dimensions, so, using the MATLAB software, it will process the image to obtain 
the Braille letter with the identification of its points, in addition to the centers and radius of each of them.

For the grayscale conversion, a weighted sum was made taking the values of each pixel that have the image of each dimension and then multiplied with a parameterized value as shown below [8]:

$$
0.2989 * R+0.5870 * G+0.114 * B
$$

After having the grayscale image being this of 2 dimensions as shown in Figure 3 (a), it proceeded to find the edges of the points that have each letter in Braille format, the Roberts Method was used, because it's very easily identifies the diagonal and linear edges, also has the ability to fill spaces [9]. Roberts's method uses a filter that focuses on each pixel following the formula below:

$$
\begin{aligned}
& \frac{d f}{d x}=f(x+1, y)-f(x, y) \\
& \frac{d f}{d y}=f(x, y+1)-f(x, y)
\end{aligned}
$$

Where to locate the pixel $(\mathrm{x}, \mathrm{y})$ that is in the ranges from 0 to 255 , if the areas have a constant intensity, it will convert them to 0 , thus giving the edges of the points.

The next step is to improve the shape of the edges that is why the Morphological Structure Method is used in the form of a square because an area that contains all the points of a letter in Braille language is required, the formula below was followed:

$$
\delta_{B}(X)=X \oplus B=\left\{x \mid X \cap B_{x} \neq \emptyset\right\}
$$

Where, it is indicated that $\mathrm{X}$ will go through the whole image, when it passes through $\mathrm{B}$, it will provide the information of the data of the neighbors of that pixel converting to the maximum value of the environment of that neighborhood defined by the element of the structure resulting in Figure 3 (b), where it is verified that within the white objects are the points [10].

The central points are then identified as shown in Figure 3 (c), where the following code was used to identify the "centroids" of the objects:

regionprops(object_image,'centroid')

The main function of it is to verify the sizes of the $\mathrm{X}$ and $\mathrm{Y}$ axes, and then divide them independently to obtain the midpoint of the object.

The following is to cut each object for a personalized analysis of each letter in Braille format, for this process the centers previously found were used and then estimate the dimensions that each letter can have in Braille format, for this process the following code was used:

imcrop(image_real,'Position',[centroids(1,1)-60 centroids(1,2)-85 120 170]);

This cutting process is done to the image in grayscale because it requires the visualization of the large and small points that have www.astesj.com the word in Braille format, as shown in Figure 3 (d) where there are two separate letters and cropped.

The next thing is to find the big points of the cropped image, for that the reader had to binarize the image to eliminate the small points and get to measure and identify the diameter of the large points and colour them red, as shown in the Figure 3 (e), for this process the following code was used:

[center_large,rad_large]=imfindcircles(image_binary,[20 20], 'ObjectPolarity','dark', 'Sensitivity',1);

large_points=viscircles(center_large,rad_large,'Color','r');

In where, it is the center of each circle as well as the radii of each of them.

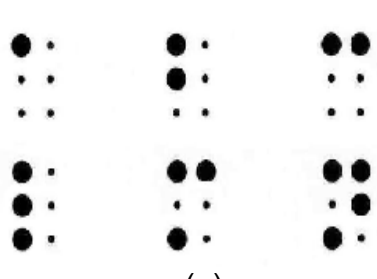

(a)

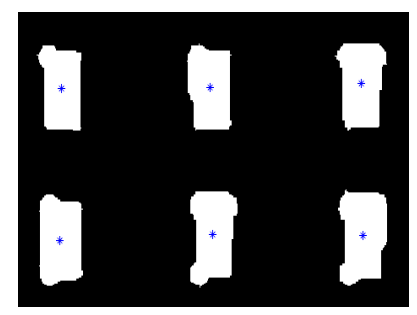

(c)

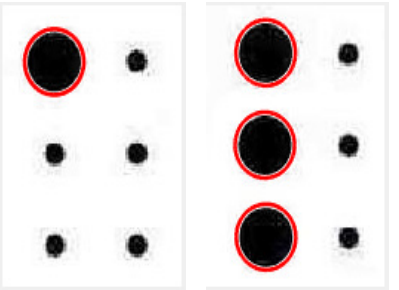

(e)

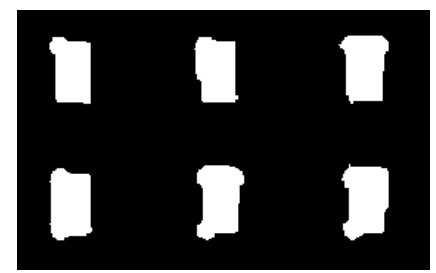

(b)

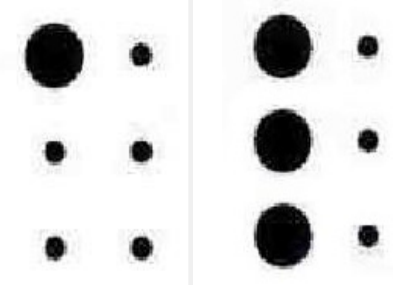

(d)

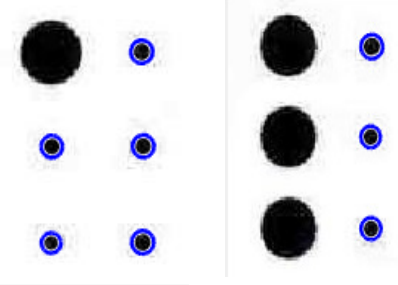

(f)

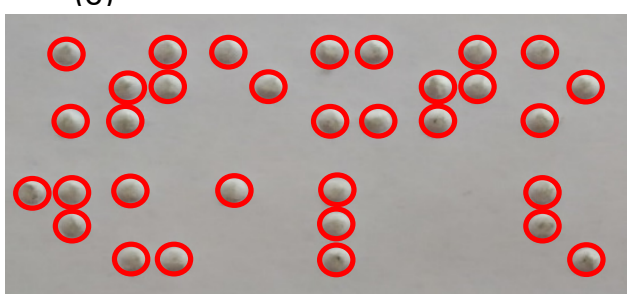

(g)

Figure 3: (a) Grayscale Image. (b) Edge detection with Roberts's method and square-shaped enhancement filter. (c) Identification of the Centers of each Object found. (d) Cut out the letters in Braille format. (e) Identification of the Largest Points. (f) Identification of the Smallest Points. (g) Fragment from a Braille Book
- Binarize the image, it means getting the image at 1 and 0 . 
- Then, use a filter that makes sectored and not eliminate the smallest objects in the image for the following process the following code was used:

bwpropfilt(bw_filter,'perimeter',6-length(rad_large), 'smallest');

The number of large points obtained previously is used and then it subtracts it with 6 which are the maximum points that represent a letter in Braille format, and it indicates that it only require the smallest objects so the software could give the small points. The following code was used to identify the points and their radii:

[center_small,rad_small] $=$ imfindcircles(bw,[5

8],'ObjectPolarity','dark', 'Sensitivity',0.98);

Small_points=viscircles(center_small,rad_small,'Color','b');

The final result is Figure 3 (e), so in this way, the identification of the large and small points in the representations of the words in Braille format is obtained.

This process of identifying the large and small points will serve as how to convert it to a binary matrix and thus differentiate each letter in Braille format by its own identification number.

Table 1: Accuracy of Translation

\begin{tabular}{|c|c|c|}
\hline \multirow[b]{2}{*}{ Class } & \multicolumn{2}{|c|}{ Predicted class } \\
\hline & $\begin{array}{l}\text { Positive } \\
\text { Predictive } \\
\text { Value }\end{array}$ & $\begin{array}{c}\text { False } \\
\text { Discovery } \\
\text { Rate }\end{array}$ \\
\hline $\mathbf{A}$ & $100.0 \%$ & $0 \%$ \\
\hline B & $100.0 \%$ & $0 \%$ \\
\hline $\mathbf{C}$ & $100.0 \%$ & $0 \%$ \\
\hline D & $100.0 \%$ & $0 \%$ \\
\hline $\mathbf{E}$ & $100.0 \%$ & $0 \%$ \\
\hline $\mathbf{F}$ & $100.0 \%$ & $0 \%$ \\
\hline $\mathbf{G}$ & $100.0 \%$ & $0 \%$ \\
\hline $\mathbf{H}$ & $100.0 \%$ & $0 \%$ \\
\hline I & $100.0 \%$ & $0 \%$ \\
\hline $\mathbf{J}$ & $100.0 \%$ & $0 \%$ \\
\hline $\mathbf{K}$ & $100.0 \%$ & $0 \%$ \\
\hline $\mathbf{L}$ & $100.0 \%$ & $0 \%$ \\
\hline M & $100.0 \%$ & $0 \%$ \\
\hline $\mathbf{N}$ & $100.0 \%$ & $0 \%$ \\
\hline$\tilde{\mathbf{N}}$ & $100.0 \%$ & $0 \%$ \\
\hline $\mathbf{O}$ & $100.0 \%$ & $0 \%$ \\
\hline $\mathbf{P}$ & $100.0 \%$ & $0 \%$ \\
\hline $\mathbf{Q}$ & $100.0 \%$ & $0 \%$ \\
\hline $\mathbf{R}$ & $100.0 \%$ & $0 \%$ \\
\hline $\mathbf{S}$ & $100.0 \%$ & $0 \%$ \\
\hline$T$ & $100.0 \%$ & $0 \%$ \\
\hline $\mathbf{U}$ & $100.0 \%$ & $0 \%$ \\
\hline $\mathbf{V}$ & $100.0 \%$ & $0 \%$ \\
\hline $\mathbf{W}$ & $100.0 \%$ & $0 \%$ \\
\hline $\mathbf{X}$ & $100.0 \%$ & $0 \%$ \\
\hline $\mathbf{Y}$ & $100.0 \%$ & $0 \%$ \\
\hline $\mathbf{Z}$ & $100.0 \%$ & $0 \%$ \\
\hline
\end{tabular}

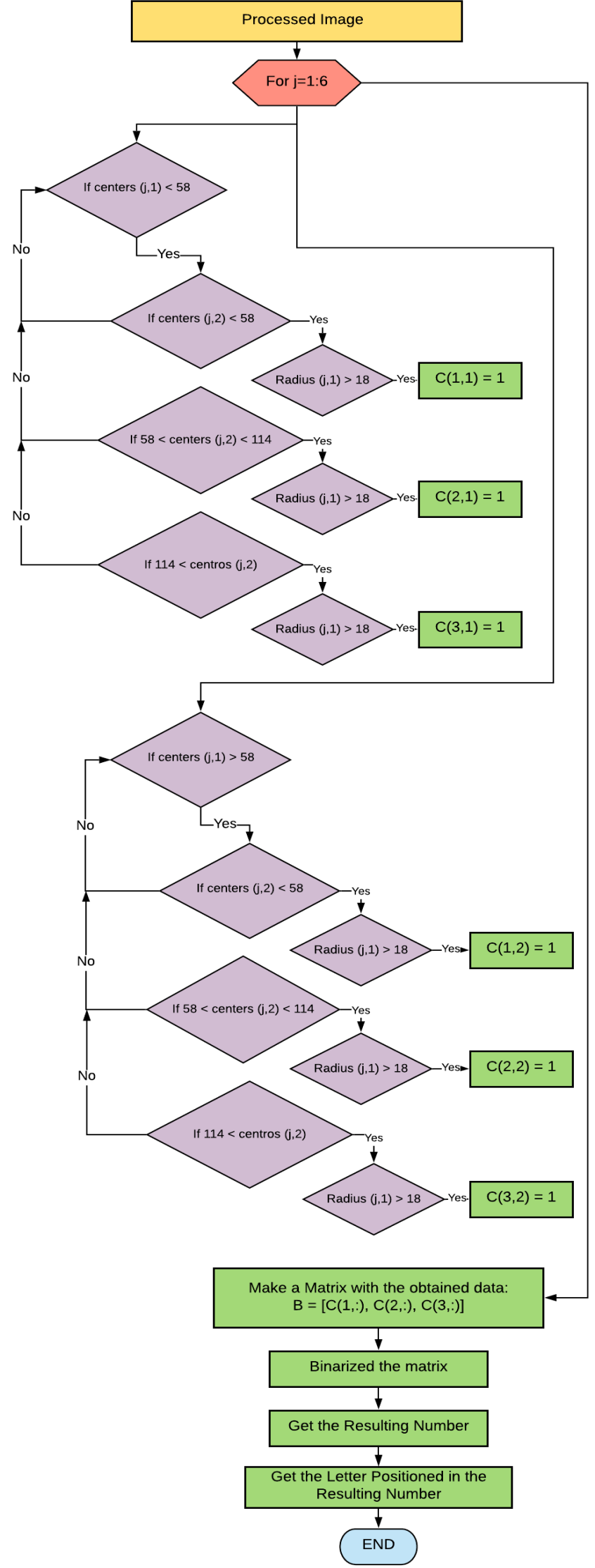

Figure 4: Flowchart of the Conversion of the Image to Matrix and Obtaining Results. 


\section{B. Meneses-Claudio et al. / Advances in Science, Technology and Engineering Systems Journal Vol. 5, No. 1, $403-407$ (2020)}

The resulting image will be processed in a loop as shown in Figure 4, which will cover the 6 points that have a letter in Braille, when it detects that there is a large point, it will convert it to a logical 1 and when it detects small points, it will convert to a logical 0 and get a $3 \times 2$ matrix. Finishing, this matrix will become binary and will be added, to obtain a number that identifies each letter, and so when it enters images, the algorithm will be able to identify the letter in the Peruvian vocabulary.

For example, when it processes the letter "L" in Braille format, it obtains a matrix, then binarize it in base 2 , make an addition with the numbers and finally it obtains the identifying number for each letter:

$$
\begin{array}{llllllll}
- & 10 & 2^{0} & 2^{1} & 2^{2} & 2^{3} 2^{5} 2^{6} \\
- & 10=1 & 0 & 1 & 0 & 1 & 0 \\
- & 10
\end{array}
$$

\section{Results}

Tests were made with 4 images of texts found on the Internet and 2 text from a book in Braille as can see in Figure $3(\mathrm{~g})$. In each image, each of the letters of the Spanish alphabet was identified, resulting in a $100 \%$ percent of translation, as shown in Table I.

These results indicate that the program is capable of translating the Braille language into Spanish vocabulary just by finding the large and small points that have a letter. In addition, it was indicated that the system was made with 6 images with the same resolution, in addition to applying several filters to improve the image because they are very small.

As mentioned above, these results are testing with lowercase Braille letters because a larger matrix format is required for uppercase, which is a matter of adding parameters to the program so the reader can translate uppercase letters in Braille format.

This paper confirms the use of image processing for translate Braille text to Spanish text, also it could record as an audio, and this will be a future work. Also, the process could be inverse with the use of image processing. The main purpose is the translation of Braille letters in Spanish to Peruvian Letters in Spanish.

\section{Discussion and Conclusions}

The research work confirms the use of image processing for the translation of the letters in Braille format to Spanish letters, in addition, that at the moment tests were made with lowercase letters having their matrix of $3 \times 2$.

This type of technology can be applied in educational centers to help the teaching of people with visual disabilities and also train teachers so that they can communicate with students with these deficiencies, therefore, improve social inclusion and study completion statistics by these people.

Braille translation systems is the vast majority tend to be expensive and very difficult access to schools or people who require the system, because of this, the research work is presented to provide open source how to make your Braille language translators.

It is concluded that the binary mode and morphological improvement filters help the image processing because the letters in Braille format are very small and when they are processed, they tend to form distorted pixels giving errors.

It is concluded that to find the large and small points can be done without the need to use an edge analyzer, as was shown in this research work, the reader can use the discard method and indicate that the software searches for small objects and will find them.

It is concluded that each process is independent, so it is necessary to use and assign different variables so that the image processing has an adequate order.

As a work in the future, we want to test the algorithm with books and a webcam to obtain the images in real time, so to know if under movement or image resolution tests the translation changes or errors are generated. Also, attach it to an electronic circuit to make the system portable.

\section{Conflict of Interest}

The authors declare no conflict of interest.

\section{References}

[1] J. A. A. Pauta, E. P. Vélez and L. Serpa-Andrade, "Braille teaching electronic prototype," 2016 IEEE International Autumn Meeting on Power, Electronics and Computing (ROPEC), Ixtapa, 2016, pp. 1-7. https://doi.org/10.1109/ROPEC.2016.7830573

[2] El correo, "la desercion en los estudiantes con discapacidad visual", 2018 [Online]. Available https://diariocorreo.pe/peru/la-desercion-escolar-en-losestudiantes-con-discapacidad-visual-807248/.

[3] DISCAPNET, "Lenguaje Braille", 2017 [Online]. Available https:/www.discapnet.es/areas-tematicas/diseno-para-todos/accesibilidadde-comunicacion/lenguaje-braille

[4] P. Petrantonakis, V. Kosmidou, M. Nikolaraizi, S. Koutsogiorgou and L. J. Hadjileontiadis, "'SEE and SEE": An Educational Tool for Kids with Hard of Hearing," 2008 Eighth IEEE International Conference on Advanced Learning Technologies, Santander, Cantabria, 2008, pp. 1032-1033. https://doi.org/10.1109/ICALT.2008.45

[5] S. Molina, B. Pérez and J. Gómez, "Literary Braille language translator to Spanish text," 2016 IEEE International Conference on Automatica (ICAACCA), Curico, 2016, pp. https://doi.org/10.1109/ICA-ACCA.2016.7778514

[6] A. Dasgupta, D. Seth, A. Ghosh and A. Nath, "Real time sign language to Braille interfacing system," 2017 7th International Conference on Communication Systems and Network Technologies (CSNT), Nagpur, 2017, pp. 371-375. https://doi.org/10.1109/CSNT.2017.8418569

[7] N. Sojib and M. Zafar Iqbal, "Single Cell Bangla Braille Book Reader for Visually Impaired People," 2018 International Conference on Bangla Speech and Language Processing (ICBSLP), Sylhet, 2018, pp. 1-4. https://doi.org/10.1109/ICBSLP.2018.8554607

[8] Brian Meneses-Claudio, Witman Alvarado-Díaz, Fiorella Flores-Medina, Natalia I. Vargas-Cuentas and Avid Roman-Gonzalez, "Muscles Heating Analysis in Sportspeople to Prevent Muscle Injuries using Thermal Images" International Journal of Advanced Computer Science and Applications(IJACSA), 10(6), 2019. https://doi.org/10.14569/IJACSA.2019.0100606

[9] B. Meneses-Claudio, W. Alvarado-Díaz, F. Flores-Medina, N. VargasCuentas, and A. Roman-Gonzalez, "Detection of Suspicious of Diabetic Feet using Thermal Image," International Journal of Advanced Computer Science and Applications(IJACSA), vol. 10, no. 6, pp. 379-383, 2019. https://doi.org/10.14569/IJACSA.2019.0100648

[10] S. Gnanapriya, P. Esakkipriya, R. Kavipriya, C. Sangeethakamatchi and M. Sandhya, "Identification of organic fruits using color and size features," 2017 IEEE Technological Innovations in ICT for Agriculture and Rural Development (TIAR), Chennai, 2017, pp. 160-163. https://doi.org/10.1109/TIAR.2017.8273707 